\title{
Serum cytokine levels and $T$ lymphocyte subsets in pregnant women with eclampsia
}

\author{
Bolanle O. P. Musa ${ }^{1 *}$, Geoffrey C. Onyemelukwe ${ }^{1}$, Olubunmi A. Olatunji ${ }^{2}$, \\ Kingsley O. Odogwu ${ }^{2}$, Joseph O. Hambolu ${ }^{3}$, Terfa S. Kene ${ }^{4}$ \\ ${ }^{1}$ Immunology Unit, Department of Medicine, Ahmadu Bello University Teaching Hospital, Zaria, Nigeria; \\ *Corresponding Author: bolamusa2002@yahoo.com \\ ${ }^{2}$ Department of Obstetrics and Gynaecology, Ahmadu Bello University Teaching Hospital, Zaria, Nigeria \\ ${ }^{3}$ Department of Veterinary Anatomy, Faculty of Veterinary Medicine, Ahmadu Bello University, Zaria, Nigeria \\ ${ }^{4}$ Community Medicine Department, Ahmadu Bello University, Zaria, Nigeria
}

Received 19 April 2012; revised 17 May 2012; accepted 28 May 2012

\section{ABSTRACT}

Background: Eclampsia, defined as the occurrence during pregnancy of hypertension, oedema, proteinuria and/or other neurologic abnormalities, causes substantial morbidity and mortality for both mother and foetus. However, its aetiology is largely unknown. Genetic and immune factors may play a role including a reduced maternal response to paternal antigen and an altered adaptation of the maternal immune system to the foetus. Methods: Participants consisted of pregnant women with and without a diagnosis of eclampsia $(N=20$, each group), and normal healthy nonpregnant controls $(\mathrm{N}=18)$. Women with smear positive malaria or clinical infections were excluded. Serum levels of TNF $\alpha$ and IL-10 were assayed by ELISA. $T$ lymphocyte subsets of pregnant patients with and without eclampsia were also studied by direct immunofluorescence using monoclonal antibodies and compared with the control group of 18 normal healthy nonpregnant women (NHC). Results: Eclampsia was associated with significantly lower mean serum IL-10 levels compared to normal pregnant and nonpregnant controls. Levels of the pro-inflammatory cytokine TNFa were higher in pregnant women with and without eclampsia, compared to control nonpregnant women. Further differences on serum cytokine levels were observed in the significantly increasing ratio of IL-10 to TNF $\alpha$ from nonpregnant controls to normal pregnant women and to pregnant women with eclampsia. The mean values of CD3+ and CD4+ positive lymphocytes was significantly decreased in patients with eclampsia $(p<0.05)$ in this study compared to pregnant controls. Similarly, CD3+ and CD4+
T cells were further decreased in eclampsia and pregnant controls compared to nonpregnant controls $(p<0.05)$. A decreasing CD4/CD8 ratio was observed from non-pregnant to pregnant controls and to patients with eclampsia buttressing an increase in CD8+ cells in eclampsia and pregnancy compared to controls. Conclusions: While a pro-inflammatory immune milieu during pregnancy complicated with eclampsia was demonstrated, the presence of eclampsia was not associated with further cytokine differences.

Keywords: Eclampsia; Cytokines; TNF $\alpha$

\section{INTRODUCTION}

In recent years, there has been a marked increase in Africa in terms of the mortality associated with eclampsia [1]. In Nigeria, fatal eclampsia in a single hospital in Ibadan, over a ten year period was observed in over $1 \%$ of births [2], while in Korle-Bu teaching hospital, Ghana, Acquaah-Arhin and Kwawukume [1] found that the incidence of eclampsia had risen from 11.2 to 15.82 per 1000 deliveries.

Eclampsia is a condition of pregnancy of unknown or speculative causation, manifesting most commonly in first pregnancies with raised blood pressure, oedema and albuminuria accompanied by fits or convulsions [3]. Susceptibility to eclampsia varies between individuals and the fact that some women are more susceptible than others implies some form of genetic and/or immune aetiology or regulation [3-5]. In a comparison of maternal cell mediated immunity (CMI) to fetal human leucocyte antigens (HLA) in normal and eclamptic pregnancies Sargent, Redman and Stirrat [5], found that normal pregnancy did not elicit any proliferative response of 
CMI to fetal HLA but eclamptic pregnancies showed differences from those of normal pregnancies indicating an abnormal immune response.

Increasingly the role of the immune response in non infectious conditions is emerging as aberrations in lymphocyte and cytokine patterns may result in some form of immune deviation affecting the T-helper1 (TH1) or T-helper2 (TH2) cellular response and these anomalies may be associated with poor outcomes as seen in eclampsia. Thus susceptibility to complications in disease may be caused in part by functional polymorphisms and mutations in genes controlling these lymphocytes and their effector pathways. The question of what changes are affected in $\mathrm{T}$ cell and cytokine levels of Nigerian patients with eclampsia forms the basis for this study. The specific objective was to perform an analysis of T cell subsets and cytokines (TNF- $\alpha$ and IL-10) in patients with eclampsia and to compare the data obtained with values in normal pregnant women and normal healthy nonpregnant controls in a bid to understand the importance of these immune components in the pathogenesis of eclampsia.

\section{MATERIALS AND METHODS}

\subsection{Study Design}

The study site was the Ahmadu Bello University Teaching Hospital (A.B.U.T.H.) Zaria, located in Kaduna State, Nigeria. It is a tertiary health facility, sub serving a substantial primary care function to its immediate environs. Patients requiring specialized emergency attention such as eclampsia are usually referred.

The study being a hospital based research, showcased the <floating > population which is typical of hospital based studies [6], was time-frame based (in this case 2 years) and non-randomized with patients taken as soon as they present. The sampling was purposive and consecutive. The study was also controlled for confounders by matching for age, parity and gestational age.

\subsection{Inclusion Criteria}

Eclampsia was defined according to the criteria of hypertension (blood pressure measurements greater than $140 / 90 \mathrm{mmHg}$ on at least two occasions 6 hours apart) developing in a pregnant patient whose blood pressure was normal before the third trimester of pregnancy; edema and proteinuria (greater than $++\{>300 \mathrm{mg} / \mathrm{dl}\}$ as assessed by a dipstick on two occasions) occurring after 20 weeks gestation, accompanied by hyperreflexia and convulsions $[7,8]$. Gestational age was determined at booking from the last menstrual period, by fundal height measurement or by ultrasonography.

Pregnant controls were selected if they were in their late third trimesters, age and parity matched with the eclamptics, had blood pressure measurements $<140 / 90$, nil proteinuria and no known medical disorders. Nonpregnant controls included normotensive (BP < 140/90) women with no known medical disorders attending the family planning clinic of the A.B.U.T.H. Patients who did not fit in with the above criteria, who refused consent or who had concurrent HIV or other infections were excluded.

\subsection{Patient Selection}

The patients successfully selected were as follows:

Group 1: Thirty-two (32) patients admitted with a diagnosis of eclampsia into the eclamptic side ward of the Labour ward of the A.B.U.T.H.

Group 2: Twenty-eight (28) normal term pregnant women in their late third trimesters ( $>35$ weeks) with no known medical disorders, attending the Antenatal clinic for routine follow-up. They were age and parity matched with the patients in group 1 above.

Group 3: Twenty (20) normal, healthy non-pregnant women recruited from the Family planning clinic of the A.B.U.T.H.

\subsection{Ethical Approval}

The study was approved by the Ethical and Scientific Board of the A.B.U.T.H. and informed consent using consent forms approved for the protocol were obtained from all patients or their next of kin (in case of severely moribund patients) and control subjects.

\subsection{Specimen Collection}

Twenty (20) millilitres (ml) of blood was drawn from each subject. Three (3) $\mathrm{ml}$ of this was transferred to an EDTA bottle for determination of the basic haematological indices. Seven (7) $\mathrm{ml}$ was dispensed in a sterile plain bottle for separation of serum in two aliquots. Both aliquots were stored in tubes containing drops of Trasylol ${ }^{\mathrm{TM}}$ (aprotinin) to inhibit degradation of cytokines and were subsequently stored at $-20^{\circ} \mathrm{C}$ for assay of cytokines [9]. Ten (10) $\mathrm{ml}$ of blood was collected in preservative free heparin tubes (SIGMA, USA) for the extraction of peripheral blood lymphocytes. Blood samples were taken from all research subjects on receipt of consent, at confirmation of diagnosis and before the administration of any drugs. Blood samples were also taken from normal healthy controls after obtaining consent and treated similarly. In support of clinical diagnosis, blood, stool, urine and sputum samples were assessed for microbiological evidence of infection in patients where possible.

\subsection{Estimation of Haematological Indices}

Basic haematological indices such as complete blood 
count (CBC), differential blood count, haematocrit, as well as malaria parasites (MPs), were assessed by standard haematological procedures outlined in the standard text of Dacie and Lewis [10] as obtained in the hospital standard operating procedures. MPs were visualized by both thick and thin blood films. Serum samples of clients with positive malaria parasite films were not analysed for cytokines.

\subsection{HIV Screening}

HIV infection in the subjects was ruled out by rapid screening for HIV using the established National algorithm of double parallel rapid tests. Commercially procured kits; the Determine ${ }^{\mathrm{TM}}$ Trinity Biotech, Japan and Immunocomb®II Bi-Spot, Organics, Israel rapid parallel tests were used according to the manufacturer's instructions. Samples positive for HIV1/2 by these tests were not included for analyses in the study.

\subsection{Cytokine Assay}

Cytokine analysis for TNF $\alpha$ and IL-10 was conducted only on 20 patients with eclampsia, 20 normal pregnant controls and 18 nonpregnant controls due to exclusion of malaria infected patients and inadequacy of resources. Cytokines were assayed for on the batched samples stored at $-20^{\circ} \mathrm{C}$ in Trasylol (SIGMA, USA) by commercial high sensitivity, specific enzyme linked immunosorbent assay (ELISA) kits following the protocol outlined [11] and described in a previous study [12]. Briefly, all samples that had been frozen at $-20^{\circ} \mathrm{C}$ were thawed once at the time of assay. Samples were dispensed diluted (1: 50) along with dilutions of recombinant cytokines as standards in 96-well microtitre ELISA plates precoated with monoclonal antibody to human interleukins (IL-10, $\mathrm{TNF} \alpha$ ) and incubated at room temperature for 2 hours. The plates were then washed four times with wash buffer (PBS/0.05\% Tween 20) and incubated for two hours with anti-cytokine horse radish peroxidase (HRP) conjugate that corresponded to each of the cytokines tested. The bound enzyme was then detected by incubation in the dark with tetramethylbenzidene (TMB) and hydrogen peroxide as a substrate. The plates were scanned using a microplate reader (Bio-Rad, USA) set at the appropriate wavelength for the color forming reaction $(450 \mathrm{~nm}$ with wavelength correction set at $570 \mathrm{~nm}$ ). A standard curve was then generated from the known standards and specimen concentrations determined by comparing sample optical density with the values on the standard curve.

\subsection{Enumeration of CD3+, CD4+ and CD8+ T Cells}

\subsubsection{Separation of Lymphocytes}

The differential gradient centrifugation method of
Gupta and Good [13] was employed. Ten (10) $\mathrm{ml}$ of heparinised blood was diluted 1:2 with Eagle's minimum essential medium (MEM) adsorbed with fetal calf serum. This was layered in $7 \mathrm{ml}$ aliquots on $3 \mathrm{ml}$ of FicollHistopaque (SIGMA, USA) density gradient medium in $10 \mathrm{ml}$ tissue culture tubes (SIGMA, USA). The mixture was centrifuged (MSE,UK) at $1800 \mathrm{rpm}$ for 30 minutes at room temperature and pure lymphocytes harvested by gently removing the lymphocyte layer at the Ficoll-MEM interface with a Pasteur pipette and transferring to another $10 \mathrm{ml}$ tissue culture tube. Lymphocyte viability was tested by trypan blue exclusion test. The cells were then washed thrice with MEM by suspending in the medium and centrifuging at $1800 \mathrm{rpm}$ for 10 minutes at room temperature. After the final wash $4 \times 10^{6}$ of the cells were suspended in $1 \mathrm{ml}$ of MEM containing $100 \mathrm{ug} / \mathrm{ml}$ penicillin, $100 \mathrm{ug} / \mathrm{ml}$ streptomycin and 5\% heat inactivated adsorbed fetal calf serum (Wellcome, UK) for lymphocyte enumeration by immunofluorescence microscopy.

\subsubsection{Immunofluorescence Microscopy Technique}

Lymphocyte subsets (CD3, CD4, CD8) were enumerated using the method described in the Becton-Dickinson (BD-Pharmingen, USA) source book and corresponding monoclonal antibodies (UCHT1, QS4120, QS4122; Ancell $^{\mathrm{TM}}$ Corporation, USA) conjugated to FITC. Cells were incubated for 30 minutes in crushed ice in fifty (50) $\mathrm{uL}$ aliquots. This was taken from the lymphocyte suspension separated above and placed in small plastic tubes, with $20 \mathrm{uL}$ of the appropriate monoclonal antibody added. The cells were then settled by centrifuging at $1000 \mathrm{rpm}$ for 5 minutes at $4^{\circ} \mathrm{C}$ (Chilspin, MSE, UK) and washed twice. After the final wash, the cells were suspended in $50 \mathrm{uL}$ of MEM and placed on a sterile glass slide to be kept in the dark at $4^{\circ} \mathrm{C}$ for 15 minutes. Direct fluorescence analysis was carried out using a fluorescent microscope (Leitz Orthoplan, Germany). Random fields were screened in the dark by selecting a field, viewing under normal light to record the total number of cells in the area, then viewing the same field under ultra violet (uv) light filter and recording the number of cells which stain bright apple green peripherally as positive. Several fields were scanned until a total of 200 lymphocytes were counted. WBC counts were used to convert percentages of positively stained cells to absolute numbers of cells.

\subsection{Statistical Analysis}

Data was analyzed by the use of computer SPSS version 11.5 and GraphPad Prism 4.0 statistical programmes, and statistical significance was calculated using Student's unpaired two-tailed t-test and ANOVA with post hoc tests 
inclusive. Comparisons were made between:

Patients with eclampsia and normal pregnant controls,

Patients with eclampsia and nonpregnant controls,

Normal pregnant controls and nonpregnant controls.

A p-value of less than 0.05 was considered to be significant.

\section{RESULTS}

\subsection{Demographic and Clinical Features in Eclampsia}

The characteristics of the women included in the study are presented in Tables 1-3. The two main groups studied were as follows: Group 1 comprising 32 patients with eclampsia and Group 2 comprising 28 normotensive pregnant (NTP) patients age and sex matched with Group 1 above. A third group (Group3) served as a nonpregnant control group and comprised 21 normal healthy nonpregnant women. The first two groups were similar in age $(22 \pm 4: 22 \pm 5)$ and gestational age $(36 \pm 2: 34 \pm 3$ weeks) as well as parity at the time of the study. Forty one percent of eclamptic women in this study were between 20 - 24 years old while women less than 20 years of age represented $38 \%$ and $39 \%$ of eclamptic women and normal pregnant women respectively. Most of the eclamptics, 28 (88\%) were unbooked, not having registered at the antenatal clinic of the ABUTH while all $(100 \%)$ normotensive pregnant controls had been booked. Of the unbooked eclamptic patients many claimed to be booked at peripheral clinics within and around town but it was not possible to get any of their records at the point of admission. The major presenting complaints in patients with eclampsia included throbbing frontal headache $(93 \%)$, dizziness, vomiting, blurring of vision and pitting edema $(93 \%)$. Clonic, tonic convulsions were frequent in patients with eclampsia (93\%) along with urinary protein greater than $4+$ on dipstick $(97 \%)$. Fever was present in only $28 \%$ of these patients and sugar in their urine could only be ascertained in $6(19 \%)$ eclamptic patients. Twenty-one $(66 \%)$ of these patients had prior signs of pre-eclampsia while eleven (34\%) did not. Nulliparous women constituted the bulk in both groups $(75 \%)$ of eclamptics; (75\%) of NTP controls (Table 1). Also in both groups of patients, Hausa women constituted the ethnic bulk (67\%) followed by Yoruba (20\%), Ibo (3\%) and others $(10 \%)$. The occupational distribution of patients with eclampsia included housewife (59\%), farmer and trader $(9 \%)$ each, civil servant $(6 \%)$ and 1 tailor. There were 7 (22\%) deaths in patients with eclampsia. All patients and controls studied were seronegative for HIV by the Determine ${ }^{\mathrm{TM}}$. Trinity Biotech, Japan or Immunocomb Bi-Spot, PBS Organics rapid parallel tests.

As indicated in Table 2 antepartum and intrapartum pre-eclampsia occurred in $15(47 \%)$ and 17 (53\%) eclamp- tic patients respectively.

Intrauterine fetal death was observed in $16(50 \%)$ patients and a roughly equal number of patients (14) had live births (Table 3). The outcome of delivery was unknown in $2(6 \%)$ patients who were taken out of the ABU Teaching Hospital due to financial constraints.

\subsection{Haematological Indices in Eclampsia}

The data in Table 4 indicates the haematological indices in patients with eclampsia, normal pregnant and nonpregnant controls. The complete white blood cell count in patients with eclampsia $\left(8 \pm 3 \times 10^{9} / \mathrm{L}\right)$ was significantly higher in relation to the nonpregnant control $(7 \pm 2$ $\left.\times 10^{9} / \mathrm{L}\right)$ and normal pregnancy $\left(6 \pm 2 \times 10^{9} / \mathrm{L}\right)$ groups $(\mathrm{p}$ $<0.05)$. There was no significant difference between the differential neutrophil and lymphocyte counts and haematocrit (PCV) values between patients with eclampsia and the control groups. The mean platelet counts also progressively decreased from patients with eclampsia

Table 1. Characteristics of women included in the eclampsia study (Mean and SD).

\begin{tabular}{cccc}
\hline $\begin{array}{c}\text { Women's } \\
\text { Characteristics }\end{array}$ & $\begin{array}{c}\text { Controls } \\
\text { (nonpregnant) } \\
\mathrm{n}=20\end{array}$ & $\begin{array}{c}\text { Normal pregnant } \\
\text { controls n }=20\end{array}$ & $\begin{array}{c}\text { Eclampsia } \\
\mathrm{N}=32\end{array}$ \\
\hline Age (yrs) & $29(6)$ & $22(5)$ & $22(4)$ \\
Gestational age (wks) & - & $34(3)$ & $36(2)$ \\
Parity & $0.25(0.5)$ & $0.25(0.5)$ & $0.47(1.5)$ \\
Systolic BP (mmHg) & $100(7)$ & $110(8)$ & $170(26)^{\S}$ \\
Diastolic BP (mmHg) & $60(6)$ & $70(9)$ & $120(16)^{\S}$ \\
BMI kg/m & $28 \pm 4$ & $26 \pm 4$ & $28 \pm 6$ \\
\hline
\end{tabular}

${ }^{\S}$ Significant $t$ test $p$ value $p<0.05$ eclampsia vs. normal pregnant and/or nonpregnant controls.

Table 2. Timing of eclampsia.

\begin{tabular}{ccc}
\hline Timing of Eclampsia & Number & Percentage (\%) \\
\hline Antepartum & 15 & 47 \\
Intrapartum & 17 & 53 \\
Total & 32 & 100 \\
\hline
\end{tabular}

Table 3. Outcome of delivery in eclampsia.

\begin{tabular}{ccc}
\hline Outcome & Number & Percentage \\
\hline Live birth & 14 & 44 \\
Fresh still birth & 12 & 37 \\
Macerated still birth & 4 & 13 \\
Not known & 2 & 6 \\
\hline
\end{tabular}


Table 4. Haematological parameters of the women in the eclampsia study (mean $+\mathrm{SD})$.

\begin{tabular}{cccc}
\hline $\begin{array}{c}\text { Haematological } \\
\text { parameters of the } \\
\text { women }\end{array}$ & $\begin{array}{c}\text { Control } \\
\text { (nonpregnant) } \\
\mathrm{N}=21\end{array}$ & $\begin{array}{c}\text { Normal pregnant } \\
\text { controls } \mathrm{n}=28\end{array}$ & $\begin{array}{c}\text { Eclampsia } \\
\mathrm{n}=32\end{array}$ \\
\hline $\begin{array}{c}\text { Haematocrit PCV (\%) } \\
\quad 36 \pm 5\end{array}$ & $33 \pm 4$ & $34 \pm 6$ \\
$\begin{array}{l}\text { White blood } \\
\text { cell } \times 10^{9} / \mathrm{L}\end{array}$ & $7 \pm 2$ & $6 \pm 2$ & $8 \pm 3^{* *}$ \\
$\begin{array}{c}\text { Neutrophil (\%) } \\
\text { Leukocyte (\%) }\end{array}$ & $50 \pm 8$ & $55 \pm 11$ & $56 \pm 13$ \\
Basophil (\%) & $2 \pm 1$ & $38 \pm 8$ & $37 \pm 11$ \\
Platelet $\times 10^{9} / \mathrm{L}$ & $214 \pm 44$ & $224 \pm 43$ & $233 \pm 46$ \\
Malaria parasites & 2 & 4 & 12 \\
\hline ** values the result of Students $\mathrm{t}$ test: $\mathrm{p}<0.05$ eclampsia vs. both controls.
\end{tabular}

$\left(233 \pm 46 \times 10^{9} / \mathrm{L}\right)$ to normal pregnant controls $(224 \pm 43$ $\left.\times 10^{9} / \mathrm{L}\right)$ and to nonpregnant controls $\left(214 \pm 44 \times 10^{9} / \mathrm{L}\right)$ although the decrease was not significant $(\mathrm{p}>0.05)$.

\subsection{T Cell Subsets in Eclampsia Study}

Total lymphocyte and $\mathrm{T}$ cell subset values in patients with eclampsia, as well as pregnant and non- pregnant controls are shown in Table 5. T cell subsets in patients with eclampsia displays decreased lymphocyte subpopulations. Pregnant and non-pregnant controls have significantly higher percent values of total $\mathrm{T}$ lymphocytes $(\mathrm{CD} 3+)$ and helper/inducer $\mathrm{T}$ cell $(\mathrm{CD} 4+)$ absolute and percentage values than patients with eclampsia $(\mathrm{p}<0.05)$. Absolute values of total $\mathrm{T}$ cells $(\mathrm{CD} 3+)$ were not significantly different between patients with eclampsia and controls, pregnant or nonpregnant $(\mathrm{p}>0.05)$. The proportion of CD8+ $\mathrm{T}$ lymphocytes was also not significantly different in patients with eclampsia compared to pregnant and nonpregnant controls $(p>0.05)$. The ratio of $\mathrm{CD} 4+$ to $\mathrm{CD} 8+$ cells in patients with eclampsia and pregnant controls was similar $(0.61: 0.91)$ and significantly lower than the ratio for nonpregnant controls at 1.38 .

\subsection{Cytokine Responses in Eclampsia versus Pregnant and Nonpregnant Controls}

The data in Figure 1 shows the serum levels of TNF- $\alpha$ and IL-10 in patients with eclampsia, normal pregnant and nonpregnant controls. The mean serum level of TNF- $\alpha$ rose considerably in patients with eclampsia (75 $\pm 17 \mathrm{pg} / \mathrm{mL}$; range $31-112 \mathrm{pg} / \mathrm{mL}$ ) and normal pregnant women $(76 \pm 10 \mathrm{pg} / \mathrm{ml}$; range $49-93 \mathrm{pg} / \mathrm{mL})$ compared to normal healthy controls at $47 \pm 22 \mathrm{pg} / \mathrm{mL}(\mathrm{p}<0.05)$. However there was no significant difference between

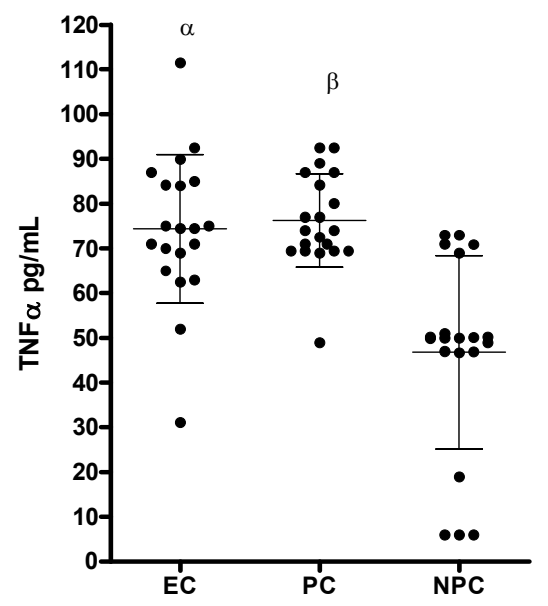

(a)

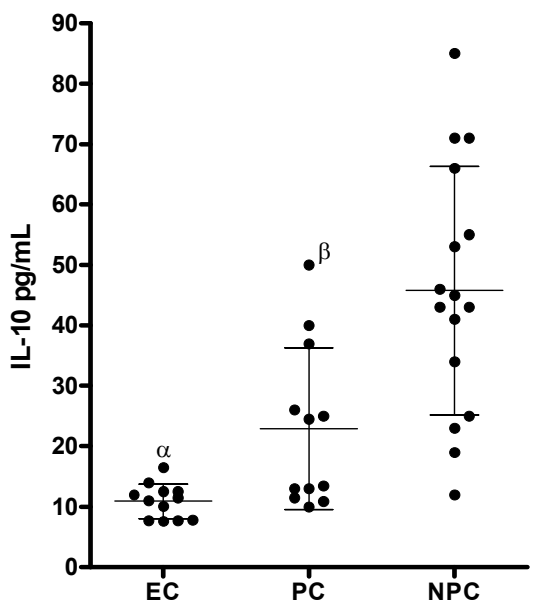

(b)

Figure 1. Serum levels of TNF $\alpha$ and IL-10 (mean $\pm \mathrm{SD}$ ) in patients with eclampsia (EC), normal healthy pregnant (PC) and healthy nonpregnant controls (NPC). (a) TNF $\alpha$ serum concentrations in patients with eclampsia $(\mathrm{EC} ; \mathrm{n}=20)$, pregnant controls $(\mathrm{PC} ; \mathrm{n}=$ 20) and Nonpregnant controls (NPC; $\mathrm{n}=$ 20). Bars represent mean and SD. ${ }^{\alpha} \mathrm{p}<0.05$ patients with eclampsia vs nonpregnant controls; ${ }^{\beta} \mathrm{p}<0.05$ Pregnant controls vs nonpregnant controls; (b) IL-10 serum concentrations in patients with eclampsia (EC; $\mathrm{n}=20$ ), pregnant controls $(\mathrm{PC} ; \mathrm{n}=20)$ and Nonpregnant controls (NPC; $\mathrm{n}=18$ ). Bars represent mean and SD. ${ }^{\alpha} \mathrm{p}<0.05$ patients with eclampsia vs nonpregnant controls; ${ }^{\beta} \mathrm{p}$ $<0.05$ Pregnant controls vs nonpregnant controls.

patients with eclampsia and normal healthy pregnant controls $(p>0.05)$.

Serum from the subgroup of 20 women with eclampsia had mean IL-10 level of $11 \pm 2 \mathrm{pg} / \mathrm{mL}$; range 4 - 37 $\mathrm{pg} / \mathrm{mL}$ compared to higher values of $21 \pm 11 \mathrm{pg} / \mathrm{ml}$; range $6-57 \mathrm{pg} / \mathrm{mL}$ seen in normal pregnant controls. 
Table 5. T-lymphocyte subsets in eclampsia, pregnant and nonpregnant controls (mean $+\mathrm{SD})$.

\begin{tabular}{|c|c|c|c|c|}
\hline Cell subset & Eclampsia $\mathrm{n}=32$ & Pregnant Control $n=28$ & Non-pregnant $\mathrm{N}=21$ & p-value \\
\hline $\mathrm{CD} 3 \%$ & $41 \pm 0.81$ & $49 \pm 0.90$ & $51 \pm 6.18$ & $<0.05^{\S}$ \\
\hline Abs CD3 & $1.23 \pm 0.50$ & $1.11 \pm 0.33$ & $1.57 \pm 0.55$ & $>0.05$ \\
\hline $\mathrm{CD} 4 \%$ & $16 \pm 1.00$ & $23 \pm 0.71$ & $29 \pm 3.16$ & $<0.05^{\S}$ \\
\hline Abs CD4 & $0.46 \pm 0.18$ & $0.51 \pm 0.15$ & $0.91 \pm 0.34$ & $<0.05^{\S}$ \\
\hline $\mathrm{CD} 8 \%$ & $26 \pm 0.12$ & $25 \pm 0.86$ & $21 \pm 3.41$ & $>0.05$ \\
\hline Abs CD8\% & $0.75 \pm 0.16$ & $0.56 \pm 0.20$ & $0.66 \pm 0.23$ & $>0.05$ \\
\hline $\mathrm{CD} 4 / \mathrm{CD} 8$ ratio & 0.61 & 0.91 & 1.38 & $<0.05^{*}$ \\
\hline
\end{tabular}

${ }^{*} \mathrm{p}$ is significant $<0.05$ between patients with eclampsia and nonpregnant controls; ${ }^{\S} \mathrm{p}$ is significant $<0.05$ between patients with eclampsia and pregnant controls.

This difference was significant $(\mathrm{p}<0.05)$. Patients with eclampsia had significantly lower mean serum levels of IL-10 compared to normal nonpregnant controls at $46 \pm 21 \mathrm{pg} / \mathrm{mL}$; range $12-100 \mathrm{pg} / \mathrm{mL}(\mathrm{p}<0.05)$. There was also a significant difference in values between normal pregnant and nonpregnant controls $(\mathrm{p}<0.05)$. The ratio of mean serum TNF- $\alpha$ to mean serum IL-10 (Figure 2) in patients with eclampsia compared to normal pregnant and nonpregnant controls was as follows: Eclampsia-6.9; pregnant controls-3.7; nonpregnant controls-1.0.

\section{DISCUSSION}

Evidence of a predominant pro-inflammatory cytokine in patients with eclampsia was the increasing trend in the ratio of TNF $\alpha$ to IL-10 from nonpregnant controls to normal healthy pregnant controls and to pregnant women with eclampsia. The results of this study showed that pro-inflammatory cytokine TNF- $\alpha$ level were present in higher concentrations in women with eclampsia compared to control nonpregnant women, though the increase was not specific for eclampsia with similar values being found in normal healthy pregnant controls. Increased production of pro-inflammatory cytokines such as IL- 6 and TNF- $\alpha$ are known to occur in normal pregnancy, pregnant women in labor and in eclampsia $[8,14]$. The results of this study confirm these findings though the underlying mechanism for the cytokinaemia might differ.

Genetic and environmental factors such as infection may play a more significant role in the generation of high levels of TNF- $\alpha$ in our pregnant patients with eclampsia even though infections were not readily detected. Falciparum as well as other malaria types are dangerous infections frequently complicating pregnancy (especially primiparae) in this environment and influencing increases in TNF $\alpha$ levels [15]. Malaria was detected in all groups in this study but incidence was highest

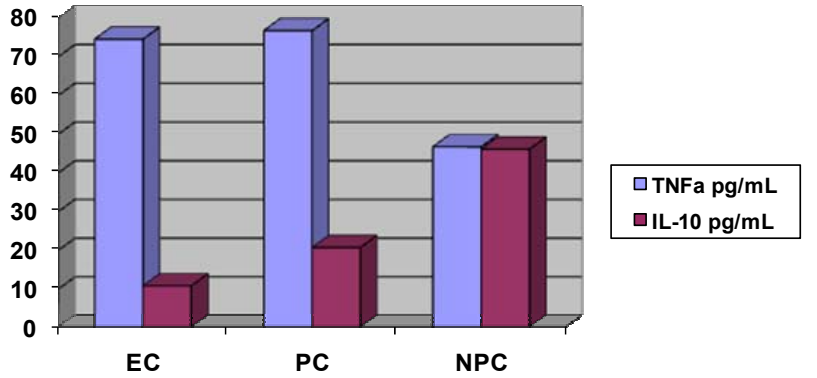

Figure 2. Mean serum levels of TNF- $\alpha$ to IL-10 in patients with eclampsia (EC), normal pregnant controls (PC) and nonpregnant controls (NPC).

in patients with eclampsia. However, with the non inclusion of patients with malaria in analysis of cytokines, $\mathrm{TNF} \alpha$ was still significantly higher in pregnant patients with or without eclampsia. Hypoglycaemia, seizures and metabolic acidosis due to reduced hepatic gluconeogenesis are proffered as reasons. Support for this is seen in pregnant mice with very low or undetectable malaria infections, where sensitivity to TNF is high resulting in hypoglycaemia, neutrophil sequestration in pulmonary vessels, liver damage, erythrophagocytosis, dyserythropoiesis and abortion $[15,16]$.

The elevation of TNF- $\alpha$ in patients with eclampsia in our study compared to nonpregnant controls could also implicate a TH1 type reactivity, infection and inflammation as factors in eclampsia and has further implications for vascular function in pregnancy. TNF- $\alpha$ in infection is associated with macrophage and neutrophil activation, inflammatory cell recruitment, upregulation of vascular adhesion molecules and acute phase proteins and $\mathrm{T}$ cell apoptosis [17]. Such infection based cytokine responses could be involved in the pathogenesis of eclampsia in this study. However since TNF- $\alpha$ levels were undertaken in women with established eclampsia, it is not possible to determine whether the increase in this cytokine is a cause or consequence of disease. Indeed previous studies have 
suggested that normal pregnancy may be associated with the generation of pro-inflammatory cytokines and that these levels are higher in women with pre-eclampsia [18]. In healthy gravidas, TNF- $\alpha$ is proposed to modulate the growth and invasion of trophoblast into maternal spiral arteries [18]. This was confirmed in a study of Ecuadorian women where levels of IL- 6 and TNF- $\alpha$ were increased more substantially during normal pregnancy and pre-eclampsia [19]. The results of Teran et al. [19] also indicated that the levels of IL- 6 and TNF- $\alpha$ detected in Ecuadorian women were significantly higher than those reported in European and North American women [18]. Levels of TNF $\alpha$ in pregnant women with or without eclampsia in this study were also higher than those reported for Caucasians. This could imply a higher propensity to TNF- $\alpha$ production in pregnant women in this environment. This could also prime the development of eclampsia or other negative pregnancy outcomes with stress and requires further study.

The mean serum IL-10 level in patients with eclampsia in this study was significantly lower than levels found in normal pregnant and nonpregnant controls. This was different from the study of Jonsson et al., [14] where levels of IL-10 did not differ between women with preeclampsia and normal pregnancies. In humans the release of IL- 10 by TH 2 cells, macrophages and B cells has been shown to be up-regulated by circulating TNF- $\alpha$ [20] with IL-10 having the ability to suppress the synthesis of pro-inflammatory cytokines from $\mathrm{T}$ cells, leucocytes and macrophages and effectively down-regulate the inflammatory response. Consequently the reverse in this study with high TNF- $\alpha$ and low IL-10 levels in patients with eclampsia compared to normal controls would indicate a defect in this counter regulatory control process and indicate an exaggeration of the pro-inflammatory response coupled with an inadequate anti inflammatory compensatory mechanism in eclampsia. The fact that this study evaluated IL-10 in a cohort of pregnant women with established eclampsia and physiologic damage could be significant. The increasing trend of $\mathrm{TNF} \alpha / \mathrm{IL}-10$ ratio from nonpregnant to pregnant then eclamptic patients indicates that IL-10 is necessary as a beneficial balance to the adverse effects of the inflammatory cytokine cascade in eclampsia. This is similar to the study by Hill et al., [21] where trophoblast activated lymphocyte supernatants from reproductively normal women contained IL-10 and IL-4, while supernatants from women with unexplained recurrent abortions (URA) had predominantly TNF- $\alpha$. It was their view that whereas TH1 type immunity to trophoblast was associated with URA and might play a role in reproductive failure, TH2 type immunity may be a natural response to trophoblast contributing to successful pregnancy. Hanna et al. [22] also indicate that tissues from normal pregnancies expressed predominantly IL-10. Similarly, Srivastava et al., [23] explain that the high IL-10 levels in human oviductal fluid plays a powerful role in regulating immune responses in the fallopian tube and endometrial cavity. IL-10 is a potent TH2 type cytokine and its deficiency in patients with eclampsia in this study in relation to increased TNF- $\alpha$ levels in same individuals may explain the adverse clinical outcome of eclampsia (50\%) child and $22 \%$ maternal mortality) compared to normal pregnant women with equally high levels of TNF- $\alpha$ but adequately compensating levels of IL-10.

Pregnant women with eclampsia had significantly higher total white blood cell counts (WBC) compared to normal pregnant women. Similarly the total white blood cell count (WBC) increased substantially in pregnant controls compared to nonpregnant controls. While the mean percentage neutrophil and mean absolute platelet counts were higher in women with eclampsia compared to pregnant controls, this did not reach significance. A similar non significant trend of an increase in neutrophil and platelet counts was observed in pregnant compared to nonpregnant controls. The elevated platelet counts in women with eclampsia in this study is in contrast to the well known significantly lower platelet counts recorded in women with pre-eclampsia compared to normal pregnant and nonpregnant controls but buttresses the significant presence of an inflammatory process in eclampsia [7]. The fact that women in this study had established eclampsia not pre-eclampsia, indicating an already established inflammatory response could explain the increased cytokinaemia and the differences in our results. Platelets participate in cellular aggregation and blood clotting in damaged blood vessels and in leucocyte-endothelial cell interactions as seen in inflammatory responses while neutrophils are the principal cells in acute inflammation and response to pathogens [24].

The mean values of $\mathrm{CD} 3+$ and $\mathrm{CD} 4+$ positive lymphocytes was significantly decreased in patients with eclampsia $(\mathrm{p}<0.05)$ in this study compared to pregnant controls. Similarly, CD3+ and CD4+ T cells were further decreased in eclampsia and pregnant controls compared to nonpregnant controls $(\mathrm{p}<0.05)$. This is similar to the report of Tallon et al., [25], where absolute numbers of total peripheral blood lymphocytes, OKT3+ (Total T-) and $\mathrm{OKT}_{4}^{+}$(Helper T-) cells decreased significantly in the second and third trimester returning to normal post partum. Mean total T-cell counts have been found to be decreased in various trimesters as compared to nonpregnant controls and mean active T-cell levels have also been found to be significantly decreased in the first and second trimesters of pregnancy [26]. Other reports of eclampsia have showed conflicting data of no significant change and a decrease in the percentage and absolute numbers of T lymphocytes [27,28], while Sridama et al. 
[29] report a reduction in total $\mathrm{T}$ cells at the expense of the helper $\mathrm{T}$ cell subset and a low ratio of helper to suppressor $\mathrm{T}$ cells in normal pregnant women. Both normal pregnant and eclamptic pregnant women in this study were in their third trimesters when women have been found to have significant reductions in peripheral blood lymphocyte levels and this could be responsible for the low values recorded.

Mildly depressed levels of peripheral $\mathrm{T}$ lymphocytes have been associated with protection of the fetus and its maintenance as an allograft. However in this study a significant reduction in CD4+ cells was found in the peripheral $\mathrm{T}$ cell compartment of patients with eclampsia compared to pregnant and nonpregnant controls. This could be due to sequestration of lymphocytes as a result of nitric oxide (NO) induced adhesion of leukocytes to the endothelium, immunosuppressive effect of hormones in pregnancy, malaria parasitaemia with its attendant immunosuppresion or a shift in $\mathrm{T}$ cell profile towards TH1 reactivity. Acute blockade of endothelial NO generation due to proinflammatory cytokine induced impairment of endothelial dependent relaxation causes constriction of resistance vessels, hypertension, altered platelet reactivity and adhesion of leukocytes to the endothelium [19]. These presumed "defence" mechanisms are said to cause cellular processes to be reduced to mere "housekeeping" roles via cell hibernation or cell stunning [30] and could be responsible for the severe organ dysfunction seen in eclampsia. The local pattern of hormone expression in pregnancy is also said to regulate lymphocyte effector mechanisms [24]. There is a suggestion that the relatively poor antigenicity of gonadotrophins (such as human chorionic gonadotrophin-HCG) in man is due to immune tolerance resulting from exposure of the fetus to very high levels of HCG in utero [31]. Even though levels of HCG were not assessed in this study, the possibility of low levels of $\beta \mathrm{HCG}$ being associated with poor $\mathrm{T}$ cell responses in eclampsia cannot be ruled out. The steroidal and immunosuppressive affects of other pregnancy hormones such as beta-lactogen and oestrogen [32], immunosuppressive factors from the placenta and the attendant reduction in the intrinsic competence of lymphocytes from pregnant women are well known [33] and may contribute to impaired cellular responses in pregnant patients in this study. Recently the presence in the placenta of trophoblast expressed indoleamine2, 3-dioxygenase (IDO) said to consume all available tryptophan and resulting in killing of maternal immune cells by amino acid starvation has been reported [34]. Alternatively the changes in CD3 and CD4 T cell percentages in this study may be as a result of subclinical dietary deficiencies, or infection. A decreasing CD4/CD8 ratio was observed from non-pregnant to pregnant controls and to patients with eclampsia buttressing an increase in sup- pressor cells in eclampsia compared to controls.

In conclusion, the presence of very low levels of IL-10 in pregnant women with eclampsia in Zaria, as opposed to the predominant inflammatory TNF $\alpha$ cytokine as well as low helper $\mathrm{T}$ lymphocyte counts, is evidence of an inflammatory pathology contributing to a predisposition to severe disease, especially in an infection endemic environment.

\section{ACKNOWLEDGEMENTS}

The study wishes to acknowledge the excellent technical assistance of Dr. T. S. Kene in analyzing the data, as well as the effort of Prof. G. C. Onyemelukwe in sourcing the cytokines.

\section{REFERENCES}

[1] Acquaah-Arhin, R. and Kwawukume, E.Y. (2003) Trends in Eclampsia at Korle-Bu Teaching hospital, Accra, Ghana. Nigerian Journal of Clinical Practice, 6, 1-4.

[2] Konje, J.C., Obisesan, K.A., Odukoya, K.A. and Ladipo, O.A. (1992) Presentation and management of eclampsia. International Journal of Gynecology \& Obstetrics, 38, 31-35. doi:10.1016/0020-7292(92)90726-Y

[3] Colli, E., Bertulessi, C., Landon, M. and Parrazzini, F. (1996) Bacterial vaginosis in pregnancy and preterm birth: Evidence from literature. The Journal of International Medical Research, 24, 317-324.

[4] Ekwempu, C.C. (1980) Infection as a possible trigger factor in the genesis of eclampsia. Tropical Doctor, 10, 174-178.

[5] Sargent, H., Redman, C.W.G. and Stirrat, G.M. (1982) Maternal cell mediated immunity in normal and preeclamptic pregnancy. Clinical \& Experimental Immunology, 50, 601-609.

[6] Coggon, D, Rose, G. and Barker, D.J.P. (2002) Epidemiology for the uninitiated. 4th Edition, Churchill-Livingstone, Edinburgh, 22.

[7] Sibai, B.M. (1996) Drug therapy: Treatment of hypertension in pregnant women. New England Journal of Medicine, 335, 1-10.

[8] Anim-Nyame, N., Sooranna, S.R., Jones, J., Alaghband, Zadeh, J., Steer, P.J. and Johnson, M.R. (2001) Biochemical markers of bone turnover are elevated in preeclampsia. British Journal of Obstetrics and Gynaecology, 108, 258-262. doi:10.1111/j.1471-0528.2001.00068.x

[9] Tietz, N.W. (2001) Clinical chemistry in laboratory tests. WB Sanders, London.

[10] Dacie, J.V. and Lewis, S.M. (1991) Practical haematology. 7th Edition, Churchill Livingstone, Edinburgh, 54-79.

[11] Pathare, A, Al Kindi, S, Alnaqdy, A, Daar, S, KnoxMacauly, H. and Dennison, D. (2004) Cytokine profile of sickle cell disease in Oman. American Journal of Hematology, 77, 323-328. doi:10.1002/ajh.20196

[12] Musa, B.O.P., Onyemelukwe, G.C., Hambolu, J.O., Mamman, A.I. and Isah, A.I. (2010) Pattern of serum cy- 
tokine expression and $\mathrm{T}$ cell subsets in sickle cell disease patients in vaso-occlusive crisis. Clinical and Vaccine Immunology, 17, 602-608. doi:10.1128/CVI.00145-09

[13] Gupta, S. and Good, R.A. (1989) Subpopulations of human lymphocytes. 1. Studies in immunodeficient patients. Clinical \& Experimental Immunology, 30, 222.

[14] Jonsson Y., Ruber, M., Matthiesen, L., Berg, G., Nieminem, K., Sharma, S., Ernerudh, J. and Ekerfelt, C. (2006) Cytokine mapping of sera from women with preeclampsia and normal pregnancies. Journal of Reproductive Immunology, 70, 83-91. doi:10.1016/j.jri.2005.10.007

[15] Chen, Q., Wahlgren, M. and Schlichtherle, M. (2000) Molecular aspects of severe malaria. Clinical Microbiology Reviews, 13, 439-450. doi:10.1128/CMR.13.3.439-450.2000

[16] Pearce, J.E. and Tarleton, R.L. (2002) Overview of the parasitic pathogens. In: Kaufmann, S.H.E., Sher, A. and Ahmed, R., Eds., Immunology of Infectious Diseases, ASM Press, Washington DC, 39-52.

[17] Kaufmann, S.H.E., Sher, A. and Ahmed, R. (Eds.) (2002) Immunology of infectious diseases. ASM Press, Washington DC, 39-52.

[18] Kupfermine, M.J, Peaceman, A.M, Aderka, D, Wallach, D. and Socol, M.L. (1996) Soluble tumor necrosis factor receptors in women with pre-eclampsia. Obstetrics \& Gynaecology, 88, 420-427. doi:10.1016/0029-7844(96)00179-2

[19] Teran, E., Escudero, C., Moya, W., Flores, M., Vallance, P. and Lopez-Jaramillo, P. (2001) Elevated C-reactive protein and pro-inflammatory cytokines in Andean women with Pre-eclampsia. International Journal of Gynecology \& Obstetrics, 75, 243-249. doi:10.1016/S0020-7292(01)00499-4

[20] Ng, P.C., Li, K., Wong, R.P.O., Chiu, K., Wong, E., Li, G. and Fok, T.F. (2003) Pro-inflammatory cytokine responses in preterm infants with systemic infections. Archives of Disease in Childhood. Fetal and Neonatal Edition, 88, F209-213.

[21] Hill, J.A., Polgar, K. and Anderson, D.J. (1995) T helper 1-type immunity to trophoblast in women with recurrent spontaneous abortion. Journal of the American Medical Association (JAMA), 273, 1933-1936. doi:10.1001/jama.1995.03520480053039

[22] Hanna, N, Hanna, J, Hleb, M, Wagner, E, Dougherty, J, Balkindi, D, Padbury, J. and Sharma, S. (2000) Gestational age dependent expression of IL-10 and its receptor in human placental tissues and isolated cytotrophoblasts. Journal of Immunology, 164, 5721-5728.

[23] Srivastava, M.D., Lippes, J. and Srivastava, B.I. (1996) Cytokines of the human reproductive tract. American Journal of Reproductive Immunology, 36, 157-166. doi:10.1111/j.1600-0897.1996.tb00157.x

[24] Roitt, I, Brostoff, J. and Male, D. (2001) Immunology. Edinburgh Harcourt Publishers Ltd., 126.

[25] Tallon, D.F, Darach Corcoran, D.J, O’Dwyer, E.M. and Greally, J.F. (1984) Circulating lymphocyte subpopulations in pregnancy: A longitudinal study. The Journal of Immunology, 132, 1784-1787.

[26] Rajvanshi, V.S., Capoor, U., Shanker, R. and Upreti, S. (1981) Lymphocyte subpopulations in normal human pregnancy. Indian Journal of Medical Research, 73, 519526.

[27] Gusdon, J.P., Heise, E. R. and Herbst, G.A. (1977) Studies of lymphocyte populations in pre-eclampsia-eclampsia. American Journal of Obstetrics and Gynecology, 129, 255-2557.

[28] Birkeland, S.A. and Kristofferson, K. (1979) Pre-eclampsia-A state of mother-fetus immune imbalance. Lancet, 2, 720-725. doi:10.1016/S0140-6736(79)90645-7

[29] Sridama, V., Pacini, F., Yang, S.L., Moawad, A., Reilly, M. and DeGroot, L.J. (1982) Decreased levels of helper T cells-A possible cause for immunodeficiency in pregnancy. New England Journal of Medicine, 307, 352. doi:10.1056/NEJM198208053070606

[30] Hotchkiss, R.S. and Karl, I.E. (2003) The pathophysiology and treatment of sepsis. New England Journal of Medicine, 348, 2. doi:10.1056/NEJMra021333

[31] Devlin, J.G. (1975) Hormone resistance and hypersensitivity. In: Gell, P.G.H., Coombs, R.R.A. and Lachman, P.J., Eds., Clinical aspects of Immunology, 3rd Edition, Blackwell Publishing, Hoboken, 963-980.

[32] Jenkins, D.M. (1977) Immunological aspects of the pathogenesis of pregnancy hypertension. Clinical Obstetrics and Gynecology, 4, 665-684.

[33] Carr, M.C., Stites, D.P. and Fudenberg, H.H. (1973) Cellular immune aspects of the human fetal-maternal relationship II. In vitro response of gravida lymphocytes to phytohaemagglutinin. Cellular Immunology, 8, 448. doi:10.1016/0008-8749(73)90136-6

[34] Pier, G.B., Lyczak, J.B. and Wetzler, L.M. (2004) Immunology, infection and immunity. ASM Press, Washington DC, 315-342. 